\title{
Receipt and targeting of evidence-based psychosocial interventions for people living with psychoses: findings from the second Australian national survey of psychosis
}

\author{
C. Harvey ${ }^{1,2 *}$, J. Lewis ${ }^{2,3}$ and J. Farhall ${ }^{2,3}$ \\ ${ }^{1}$ Department of Psychiatry, University of Melbourne, Coburg, Victoria, Australia \\ ${ }^{2}$ NorthWestern Mental Health, Melbourne, Victoria, Australia \\ ${ }^{3}$ School of Psychology and Public Health, La Trobe University, Melbourne, Victoria, Australia
}

\begin{abstract}
Aims. Clinical Practice Guidelines (CPGs) recommend evidence-based psychosocial interventions (EBPIs) to improve consumer recovery; however, availability appears limited. We describe receipt of six EBPIs, reported by people with psychoses, and associations with service and consumer characteristics, including indicators of need (eligibility) and benefit (suitability).
\end{abstract}

Methods. Participants in the 2010 Australian national survey of psychosis $(n=1825)$ were interviewed to assess demographic, functional, mental and physical health characteristics and service use in the previous year. Six EBPIs (Cognitive Behaviour Therapy for psychosis; Family Psycho-Education (FPE); Relapse Prevention Planning (RPP); Skills Training; Supported Employment; and Assertive Community Treatment) were chosen, based on the strength and consistency of CPG recommendations. Associations between receipt of interventions and eligibility and suitability indicators were examined via correlations and $\chi^{2}$. Logistic regression was used to predict receipt of one or more EBPIs and to identify predictors of each individual EBPI.

Results. Less than one-quarter of the sample reported receipt of an evidence-based level of any intervention: rates ranged from $3.4 \%$ (FPE) to $21.1 \%$ (RPP). The model predicting receipt of one or more EBPIs was statistically significant $\left(\chi^{2}(20, n=1746)=216.12, p<0.01\right)$ and marginally useful. Nine variables contributed uniquely, of which six were service characteristics. The strongest predictors of receipt were being assigned a psychologist as a case manager $(p<0.01, \mathrm{OR}$ $(\mathrm{CI})=2.36(1.50-3.72))$ and accessing a non-clinical mental health support service in the past year $(p<0.01, \mathrm{OR}(\mathrm{CI})=2.01$ $(1.60-2.51))$.

Conclusions. Prior reports of limited receipt of EBPIs are reinforced. There is patchy evidence for targeting of EBPIs to those who might benefit most. Service characteristics contribute more to the prediction of receipt than clinical characteristics. Greater implementation effort and better targeting are required to bridge evidence-practice gaps, including improved evidence-based practice literacy among professionals and needs-based service re-design to improve provision and optimise consumer outcomes.

Received 5 February 2018; Accepted 12 May 2018; First published online 12 June 2018

Key words: Evidence-based psychiatry, other psychosocial techniques/treatments, population survey, psychosis.

\section{Introduction}

Clinical Practice Guidelines (CPGs) for schizophrenia (NICE, 2014; Galletly et al. 2016) recommend best available treatments and services. They include evidence-based psychosocial interventions (EBPIs) such as Cognitive Behaviour Therapy (CBT). EBPIs are

* Address for correspondence: Carol Harvey, Department of Psychiatry, Psychosocial Research Centre, University of Melbourne, 130 Bell Street, Coburg, Victoria 3058, Australia.

(Email: c.harvey@unimelb.edu.au) particularly important for people living with schizophrenia and other psychotic disorders, since many experience sub-optimal clinical recovery even with recommended medication.

There is little international data about receipt of EBPIs. A systematic review of UK studies addressing implementation of national recommendations (Ince et al. 2016) found reported rates from $4 \%$ to $100 \%$ for CBT and $0 \%$ to $53 \%$ for Family Interventions, with heterogeneity too great to allow aggregation of results. Availability appears to be limited (Harris \& Boyce, 2013; Haddock et al. 2014), except in mental health 
services that have systematic implementation programs (e.g. McHugo et al. 2007). Most studies audit conformance with CPG recommendations using clinical files (e.g. Lehman \& Steinwachs, 1998; West et al. 2005) or through service provider reports (e.g. Magliano et al. 1998; Fadden et al. 2002; Kim \& Salyer, 2008). We are not aware of studies seeking patient reports of EBPIs for psychoses, other than the Rethink survey in the UK, reported by Ince et al. (2016), which sought self-reports about receipt of CBT without specifying the definition of the treatment or duration. Further, we are unaware of systematic enquiries about the extent of receipt of EBPIs within larger population-based samples; information that is particularly helpful for national policy and funding.

No treatment is likely to be relevant to the needs of all patients. Judgements about the adequacy of observed rates of receipt of an intervention, or its targeting, should consider the numbers of people requiring the intervention. Therefore, we searched the literature for guidance on both eligibility and suitability indicators for EBPIs. We defined eligibility indicators as demographic, illness or disability-related characteristics that meet conditions for providing the intervention. For example, having regular contact with family members indicates eligibility for Family Psycho-Education (FPE). This eligibility threshold avoids including people for whom the intervention was not intended, whilst minimising exclusions. Further, the resource costs in providing EBPIs are significant; thus they are likely to be provided not just because a person meets eligibility criteria, but also because they are seen as likely to need, or benefit from, the intervention. Hence, suitability indicators were defined as intervention-specific demographic, illness or disability-related characteristics associated with better targeting, the likelihood of engagement (Fanning et al. 2012) or successful outcomes (van der Gaag et al. 2011).

Based on the strength and consistency of CPG recommendations we chose six EBPIs for study: CBT for psychosis (CBTp); FPE; Relapse Prevention Planning (RPP); Skills Training (ST); Supported Employment (SE); and Assertive Community Treatment (ACT) (See Table 1 for definitions).

With regard to eligibility and suitability criteria, we identified no eligibility restriction for CBTp (NICE, 2014; Galletly et al. 2016). Three suitability indicators were evident: persisting positive symptoms (Sivec \& Montesano, 2012); absence of comorbid substance abuse (Barrowclough et al. 2010); and fewer negative symptoms (Klingberg et al. 2011; Thomas et al. 2011), each associated with better outcome. We identified minimal literature about eligibility or suitability for FPE. It was assumed that current or recent family contact was an eligibility criterion and frequent family contact was a suitability criterion (e.g. Lehman et al. 2004; Dixon et al. 2010; NICE, 2014). For RPP, some CPGs (Lehman et al. 2004; NICE, 2014) link eligibility with recurrent episodes of disorder; however, this has not been universally adopted (e.g. Agius et al. 2007), and would exclude some patients with significant relapse risk (Alvarez-Jimenez et al. 2012). Hence we adopted no eligibility criterion. Past history (Herz et al. 2000; Gumley et al. 2003) and recency (Garety et al. 2008) of relapse have driven selection in trials, thus were included as suitability indicators.

Functional disability is a clear eligibility criterion for ST (Lehman et al. 2004; Dixon et al. 2010). Although better cognition (e.g. Ucok et al. 2006), learning skills (Silverstein et al. 2005) and neuropsychological functioning (Granholm et al. 2008) are associated with improved outcomes, ST is intended for consumers with deficits that may be associated with these factors so we did not consider them as suitability variables. Instead, we opted for indicators related to greater need: social skills difficulties and poorer role functioning. The dominant model of SE, Individual Placement and Support, has one eligibility indicator - the individual's desire to work (Bond, 2004). For suitability indicators, good evidence exists that better prior work history and education beyond secondary level are associated with better vocational outcomes (e.g. Campbell et al. 2010; Major et al. 2010). The target population for ACT is variously described as patients with longer term and complex mental health problems, difficulties in engaging with community mental health services and/or experiencing frequent admissions (Dixon, 2000; Cuddeback et al. 2006; Aagaard \& Muller-Nielsen, 2011; Brugha et al. 2012; Kortrijk et al. 2012; Killackey et al. 2015). We adopted absence of longer-term illness (i.e. single episode with good recovery) as the least exclusionary eligibility criterion and used the following suitability indicators: difficulties with engagement; frequent hospital admissions; co-morbid substance use; poor course of disorder; and poor functioning.

It is likely that demographic, clinical and service characteristics may be generally predictive of receipt of EBPIs - identifying these may indicate barriers and enablers for EBPIs. For example, having a first language other than English, symptom severity, and poorer cognitive functioning may impact engagement in, or benefit from, any EBPI. Service characteristics were also included as potential predictors since service provision is brokered by case managers and may be enabled by the involvement of an NGO (non-clinical mental health support service) (Harvey et al. 2016).

To better understand receipt of six EBPIs in Australia, and the characteristics of those who receive 
Table 1. Six evidence-based psychosocial interventions (EBPIs): definitions, corresponding SHIP survey questions and respective eligibility and suitability indicators according to peer-reviewed literature and available national psychosis survey variables

\begin{tabular}{|c|c|c|c|c|c|c|c|}
\hline EBPI & $\begin{array}{l}\text { Definition and aims (from } \\
\text { literature and CPGs) }\end{array}$ & $\begin{array}{c}\text { Corresponding } 2010 \text { national } \\
\text { psychosis survey (SHIP) } \\
\text { question }\end{array}$ & $\begin{array}{c}\text { Evidence-based level } \\
\text { adopted }\end{array}$ & $\begin{array}{l}\text { 'Strong' } \\
\text { eligibility } \\
\text { indicators } \\
\text { from literature }\end{array}$ & $\begin{array}{l}\text { Eligibility } \\
\text { indicators } \\
\text { available in } \\
\text { SHIP }\end{array}$ & $\begin{array}{l}\text { 'Strong' suitability } \\
\text { indicators from } \\
\text { literature }\end{array}$ & $\begin{array}{l}\text { Suitability indicators } \\
\text { derived from SHIP } \\
\text { variables }\end{array}$ \\
\hline $\begin{array}{l}\text { CBT for } \\
\text { psychosis } \\
\text { (CBTp) }\end{array}$ & $\begin{array}{l}\text { Reduce distress and } \\
\text { increase adaptive } \\
\text { behaviour by working } \\
\text { with thoughts and beliefs } \\
\text { that mediate emotional } \\
\text { and behavioural } \\
\text { responses, and by } \\
\text { enhancing adaptive } \\
\text { coping }\end{array}$ & $\begin{array}{l}\text { Did you receive any therapy } \\
\text { where you and your } \\
\text { therapist explored your } \\
\text { thoughts, feelings and } \\
\text { beliefs about your } \\
\text { symptoms and illness and } \\
\text { came up with new ways of } \\
\text { understanding and coping } \\
\text { with them? }\end{array}$ & Eight or more sessions & None & N/A & $\begin{array}{l}\text { Persisting positive } \\
\text { symptoms, fewer } \\
\text { negative } \\
\text { symptoms and } \\
\text { absence of co- } \\
\text { morbid substance } \\
\text { abuse }\end{array}$ & $\begin{array}{l}\text { identifying } \\
\text { 'uncontrolled } \\
\text { symptoms of mental } \\
\text { illness as a top three } \\
\text { challenge in the next } \\
\text { year'; } \\
\text { 'lack of relief from } \\
\text { medication for } \\
\text { mental health'; low } \\
\text { Carpenter negative } \\
\text { syndrome score in } \\
\text { past year (less than 2); } \\
\text { absence of 'any } \\
\text { substance use in past } \\
\text { year' }\end{array}$ \\
\hline $\begin{array}{l}\text { Family } \\
\text { Psycho- } \\
\text { Education } \\
\text { (FPE) }\end{array}$ & $\begin{array}{l}\text { Reduce consumer relapse } \\
\text { and carer burden by } \\
\text { bringing together the } \\
\text { consumer and their } \\
\text { family or other carers to } \\
\text { learn together about the } \\
\text { disorder, and build skills } \\
\text { such as communication, } \\
\text { problem solving and } \\
\text { crisis support }\end{array}$ & $\begin{array}{l}\text { Have you and your family met } \\
\text { together regularly with a } \\
\text { mental health clinician to } \\
\text { learn about mental illness } \\
\text { and improve your } \\
\text { communication and } \\
\text { problem-solving skills? }\end{array}$ & Six or more sessions & $\begin{array}{l}\text { Some contact } \\
\text { with family }\end{array}$ & $\begin{array}{l}\text { Has some } \\
\text { 'contact with } \\
\text { family } \\
\text { during past } \\
\text { year' }\end{array}$ & $\begin{array}{l}\text { Frequent contact } \\
\text { with family }\end{array}$ & $\begin{array}{l}\text { Composite indicator } \\
\text { created: } \\
\text { 'living with any } \\
\text { relative' and } \\
\text { 'at least weekly face } \\
\text { to face contact with } \\
\text { any family' }\end{array}$ \\
\hline
\end{tabular}


Table 1. Continued

\begin{tabular}{|c|c|c|c|c|c|c|c|}
\hline EBPI & $\begin{array}{c}\text { Definition and aims (from } \\
\text { literature and CPGs) }\end{array}$ & $\begin{array}{c}\text { Corresponding } 2010 \text { national } \\
\text { psychosis survey (SHIP) } \\
\text { question }\end{array}$ & $\begin{array}{c}\text { Evidence-based level } \\
\text { adopted }\end{array}$ & $\begin{array}{c}\text { 'Strong' } \\
\text { eligibility } \\
\text { indicators } \\
\text { from literature }\end{array}$ & $\begin{array}{c}\text { Eligibility } \\
\text { indicators } \\
\text { available in } \\
\text { SHIP }\end{array}$ & $\begin{array}{l}\text { 'Strong' suitability } \\
\text { indicators from } \\
\text { literature }\end{array}$ & $\begin{array}{l}\text { Suitability indicators } \\
\text { derived from SHIP } \\
\text { variables }\end{array}$ \\
\hline $\begin{array}{l}\text { Relapse } \\
\text { Prevention } \\
\text { Planning (RPP) }\end{array}$ & $\begin{array}{l}\text { Pick up early warning signs } \\
\text { of relapse in time for } \\
\text { treatment and support } \\
\text { changes that might } \\
\text { prevent a relapse, treat it } \\
\text { early or mitigate its full } \\
\text { impact }\end{array}$ & $\begin{array}{l}\text { Have you done some future } \\
\text { planning with a mental } \\
\text { health worker in which you } \\
\text { discussed your past } \\
\text { experiences of being unwell } \\
\text { and identified warning signs } \\
\text { that a relapse may occur? } \\
\text { AND } \\
\text { Have you made a written } \\
\text { plan about what you and a } \\
\text { significant other person in } \\
\text { your life, and the mental } \\
\text { health service could do if } \\
\text { those warning signs return? }\end{array}$ & $\begin{array}{l}\text { A written plan in addition } \\
\text { to the discussion }\end{array}$ & None & $\mathrm{N} / \mathrm{A}$ & $\begin{array}{l}\text { Recent history of } \\
\text { relapse and past } \\
\text { history of relapse }\end{array}$ & $\begin{array}{l}\text { 'any mental health } \\
\text { admission in past } \\
\text { year'; } \\
\text { 'multiple episodes or } \\
\text { continuous illness in } \\
\text { the course of their } \\
\text { disorder' }\end{array}$ \\
\hline $\begin{array}{l}\text { Skills Training } \\
\text { (ST) }\end{array}$ & $\begin{array}{l}\text { Address functional skill } \\
\text { difficulties through use } \\
\text { of behavioural skill } \\
\text { training or educational } \\
\text { skill teaching models of } \\
\text { change }\end{array}$ & $\begin{array}{l}\text { Have you participated in a } \\
\text { group or individual training } \\
\text { program for improving } \\
\text { social skills or independent } \\
\text { living skills, that included } \\
\text { assessment of your skills, } \\
\text { teaching and practicing new } \\
\text { skills, then trying them out } \\
\text { in your daily life? }\end{array}$ & Six or more sessions & $\begin{array}{l}\text { Functional } \\
\text { skills } \\
\text { deficits }\end{array}$ & $\begin{array}{l}\text { Greater than } \\
\text { 'only mild } \\
\text { difficulties' } \\
\text { on the } \\
\text { Personal } \\
\text { and Social } \\
\text { Performance } \\
\text { scale (i.e., } \\
\text { PSP }<71 \text { ) }\end{array}$ & & $\begin{array}{l}\text { 'illness interferes with } \\
\text { desired } \\
\text { relationships'; } \\
\text { 'dysfunction in } \\
\text { overall socialising'; } \\
\text { 'relationships } \\
\text { deteriorated due to } \\
\text { illness'; MSIF overall } \\
\text { global residential } \\
\text { rating: moderate or } \\
\text { lower role } \\
\text { performance }\end{array}$ \\
\hline
\end{tabular}




\begin{tabular}{|c|c|c|c|c|c|c|c|}
\hline $\begin{array}{l}\text { Supported } \\
\text { Employment } \\
\text { (SE) }\end{array}$ & $\begin{array}{l}\text { Assists the individual to } \\
\text { find a job in the open } \\
\text { labour market and } \\
\text { provides support to keep } \\
\text { them in that job, } \\
\text { including advice, } \\
\text { assistance with making } \\
\text { necessary adjustments in } \\
\text { the workplace (e.g. } \\
\text { changing work } \\
\text { schedules) and with } \\
\text { managing their health } \\
\text { and sources of stresses } \\
\text { within the workplace }\end{array}$ & $\begin{array}{l}\text { Did an employment support } \\
\text { worker provide you with } \\
\text { support, advice, counselling } \\
\text { or speak with your case } \\
\text { manager about your mental } \\
\text { health needs? }\end{array}$ & Six or more sessions & $\begin{array}{c}\text { Desire to } \\
\text { work }\end{array}$ & $\begin{array}{l}\text { 'Looking for } \\
\text { work' or } \\
\text { 'employed } \\
\text { during past } \\
\text { year' }\end{array}$ & $\begin{array}{l}\text { Better prior work } \\
\text { history and } \\
\text { education beyond } \\
\text { secondary level }\end{array}$ & $\begin{array}{l}\text { ‘wanted help to work or } \\
\text { use one's time'; } \\
\text { 'educated beyond } \\
\text { secondary level' }\end{array}$ \\
\hline $\begin{array}{l}\text { Assertive } \\
\text { Community } \\
\text { Treatment } \\
\text { (ACT) }\end{array}$ & $\begin{array}{l}\text { Service model defined by a } \\
\text { discrete team with a } \\
\text { small fixed caseload, } \\
\text { enabling intensive } \\
\text { practice characterised by } \\
\text { in vivo and extended hours } \\
\text { delivery of interventions } \\
\text { through assertive } \\
\text { outreach, medication } \\
\text { supervision, problem } \\
\text { resolution and } \\
\text { individualised } \\
\text { rehabilitation }\end{array}$ & $\begin{array}{l}\text { Was there a period of time } \\
\text { when your main mental } \\
\text { health care was provided by } \\
\text { a team from the mental } \\
\text { health services who } \\
\text { regularly visited you in your } \\
\text { home, in the daytime and } \\
\text { evenings, to help with your } \\
\text { mental health? }\end{array}$ & N/A & $\begin{array}{l}\text { Difficulties in } \\
\text { providing } \\
\text { treatment in } \\
\text { the context } \\
\text { of } \\
\text { prolonged } \\
\text { and } \\
\text { complex } \\
\text { illness }\end{array}$ & $\begin{array}{l}\text { Exclude } \\
\text { persons with } \\
\text { 'single } \\
\text { episode with } \\
\text { good } \\
\text { recovery' }\end{array}$ & $\begin{array}{l}\text { Difficulties with } \\
\text { engagement, } \\
\text { frequent hospital } \\
\text { admissions, co- } \\
\text { morbid substance } \\
\text { use, poor course } \\
\text { of disorder and } \\
\text { poor functioning }\end{array}$ & $\begin{array}{l}\text { 'poor functioning } \\
\text { according to PSP (i.e. } \\
\text { PSP <31)'; 'very } \\
\text { unconfident that } \\
\text { current medication is } \\
\text { a good thing for their } \\
\text { mental health'; } \\
\text { 'multiple episodes of } \\
\text { illness with partial } \\
\text { recovery or a } \\
\text { continuous illness in } \\
\text { the course of their } \\
\text { disorder'; 'two or } \\
\text { more admissions for } \\
\text { mental health in past } \\
\text { year'; 'any substance } \\
\text { use in past year'; } \\
\text { 'very dissatisfied } \\
\text { with help and } \\
\text { support received } \\
\text { from case manager'. }\end{array}$ \\
\hline
\end{tabular}


them, we used available variables from the dataset collected within the second Australian national psychosis survey (Morgan et al. 2012) to address the following questions:

1. How prevalent is receipt of one or more EBPIs within a 12-month period in a treated sample of people with psychotic disorders?

2. Are patient eligibility and suitability indicators for an EBPI associated with receipt of that intervention?

3. Are demographic and clinical characteristics of consumers, and service characteristics, associated with receipt of EBPIs?

\section{Method}

\section{Materials and methods}

Survey and participants

All participants took part in the Survey of High Impact Psychosis (SHIP). This second Australian national survey of psychosis covered seven catchment areas (total area 62000 square kilometres) with a population of 1.5 million people aged 18-64 years. A two-phase design was used (Morgan et al. 2012). During the census month (March 2010), screening for psychosis occurred in public specialised mental health services and in non-government organisations supporting people with a mental illness. In addition, those with a recorded diagnosis of psychosis and in contact with clinical services during the previous 11 months were identified from administrative records. People who screened positive for psychosis were randomly selected, stratified by age group (18-34 years and 3564 years), for interview and assessment. Of 7955 people who were screen positive and eligible, 1825 were interviewed (for full details, see Morgan et al. 2012). The study was approved by institutional human research ethics committees at each site. All participants provided written informed consent.

\section{Measures and data handling}

The interview schedule probed: demographic characteristics, education, employment, housing, symptomatology, substance use, functioning and disability, physical health, use of mental health services and medication. Externally developed instruments were used, along with questions from the previous national low prevalence disorders survey (Jablensky et al. 2000) and new questions developed specifically for the 2010 survey (Morgan et al. 2012). The diagnosis was based on the Diagnostic Interview for Psychosis (DIP-DM) (Castle et al. 2006). The number of negative symptoms was based on the Carpenter Deficits syndrome from the World Health Organization Schedules for Clinical Assessment in Neuropsychiatry, without taking attribution into account (Kirkpatrick et al. 1989; World Health Organisation, 1999). The Personal and Social Performance Scale (Morosini et al. 2000) assessed behavioural and social functioning and role performance over the previous year. The course of disorder was rated by the interviewers based on the entire interview. Premorbid and current cognitive ability were assessed using the National Adult Reading TestRevised (Nelson \& Willison, 1991) and the Digit Symbol Coding Test from the Repeatable Battery for the Assessment of Neuropsychological Status (Randolph et al. 1998), respectively.

\section{Receipt of EBPIs}

Survey questions about receipt of six EBPIs (CBTp, FPE, RPP, ST, SE and ACT) were crafted to describe each from a participant perspective. The formal names of the interventions were not used since they may not be known or correctly applied by participants. The questions, reproduced in Table 1, aimed to provide sufficient information to briefly capture the essence of the intervention whilst minimising information processing demands. An evidence-based level was specified for each intervention, except for ACT since the intervention question implied sufficient duration. These levels reflected the minimum specified in CPGs or meta-analyses, discounted by about one-third in order to minimise false negatives since some participants would not have completed a current intervention at the time of interview.

\section{Eligibility and suitability indicators for EBPIs}

Existing SHIP questions were examined for their utility as eligibility and suitability indicators for each EBPI; it was not possible to add further items to the already lengthy SHIP survey to reflect all the identified eligibility and suitability indicators. However, one eligibility item was identified for each of four EBPIs and 2-6 suitability items for each EBPI (see Table 1).

\section{General predictors of receipt of interventions}

Demographic, clinical and service characteristics collected by the survey and likely to be associated with receipt of any EBPI are listed in Table 2.

\section{Analysis}

Univariate relationships between receipt of individual EBPIs and their respective suitability indicators were examined via correlations for continuous 
Table 2. Profile of participants $(n=1825)$ on selected demographic, clinical and service characteristics, and suitability indicators for evidence-based psychosocial interventions (EBPIs)

\begin{tabular}{|c|c|c|}
\hline Demographic characteristics & $N$ reporting & $n(\%)$ \\
\hline Age group & 1825 & \\
\hline $18-34$ years & & $773(42.4)$ \\
\hline $35-65$ years $^{a}$ & & $1052(57.6)$ \\
\hline Male & 1825 & $1087(59.6)$ \\
\hline In a marital or de facto relationship & 1825 & $312(17.1)$ \\
\hline English is first language & 1825 & $1657(90.8)$ \\
\hline Completed 12 years of education & 1802 & $574(31.9)$ \\
\hline Clinical characteristics & $N$ reporting & $n(\%)$ \\
\hline Personal and social performance (PSP) score & 1825 & \\
\hline Poor functioning $(0-30)$ & & $90(4.9)$ \\
\hline Varying degrees of disability (31-70) & & $1412(77.4)$ \\
\hline Absence of disability or only mild difficulties (71-100) & & $323(17.7)$ \\
\hline Course of disorder & 1825 & \\
\hline Single episode & & $147(8.1)$ \\
\hline Multiple episodes with good recovery & & $542(29.7)$ \\
\hline Multiple episodes with partial recovery & & $580(31.8)$ \\
\hline Continuous chronic illness & & $376(20.6)$ \\
\hline Continuous chronic illness with deterioration & & $180(9.9)$ \\
\hline Insight present about disorder (lifetime) & 1825 & $1389(76.1)$ \\
\hline Lifetime diagnosis of alcohol abuse/dependence (Yes) & 1825 & $921(50.5)$ \\
\hline Lifetime diagnosis of other substance abuse/dependence (Yes) & 1825 & $995(54.5)$ \\
\hline Non-Affective Psychosis & 1825 & $1150(63.0)$ \\
\hline Positive symptoms (present state) (Yes) & 1825 & $1015(55.6)$ \\
\hline Number of negative symptoms (past year) & 1825 & \\
\hline $0-1$ & & $534(29.3)$ \\
\hline $2-4$ & & $889(48.7)$ \\
\hline $5-6$ & & $402(22.0)$ \\
\hline Digit Symbol Coding Test & 1609 & \\
\hline More than 1 S.D. below mean & & $223(14.4)$ \\
\hline Within 1 s.D. of mean & & $1124(69.4)$ \\
\hline Greater than 1 s.D. above mean & & $262(16.2)$ \\
\hline National Adult Reading Test Full Scale IQ estimate & 1546 & \\
\hline More than 1 s.D. below mean & & $267(17.3)$ \\
\hline Within 1 s.D. of mean & & $1000(64.7)$ \\
\hline Greater than 1 s.D. above mean & & $279(18.0)$ \\
\hline Service Characteristics & $N$ reporting & $n(\%)$ \\
\hline Accessed Non-Government Organisation (past year) (Yes) & 1802 & $544(30.2)$ \\
\hline Community Treatment Order in past year (Yes) & 1825 & $350(19.2)$ \\
\hline Case manager & 1100 & \\
\hline Medical registrar & & $77(7)$ \\
\hline Nurse & & $549(49.9)$ \\
\hline Psychologist & & $72(6.5)$ \\
\hline Social worker & & $310(28.2)$ \\
\hline Occupational therapist & & $92(8.4)$ \\
\hline Satisfaction with a case manager & 1261 & \\
\hline Very satisfied & & $806(63.9)$ \\
\hline Somewhat satisfied & & $279(22.1)$ \\
\hline Neither satisfied nor dissatisfied & & $84(6.7)$ \\
\hline Somewhat dissatisfied & & $49(3.9)$ \\
\hline Very dissatisfied & & $43(3.4)$ \\
\hline
\end{tabular}


Two or more mental health admissions (past year)

Note: ${ }^{\text {a }}$ The sample was limited to persons aged 18-64, but one participant had turned 65 by the time of the interview. S.D., standard deviation.

variables or $\chi^{2}$ for categorical variables, after checking that assumptions were met.

Receipt of one or more EBPIs was predicted using hierarchical logistic regression. Four blocks of independent variables were entered: demographic variables; lifetime clinical and substance use variables; mental health symptomatology; and service provision variables. Since ACT differs in being a service model rather than a single intervention, we re-ran the model excluding ACT.

Separate hierarchical logistic regressions were run for each EBPI. Where eligibility indicators were identified, the participant sample was restricted to those who met these. The same four blocks of independent variables were used as for the first regression analysis; a fifth block was added to include specific suitability indicators if identified in univariate analyses.

Variables in blocks one to four (demographic; lifetime clinical and substance use; mental health symptomatology; and service provision) were chosen on a priori grounds. Given that our earlier univariate suitability analyses were designed to identify suitability indicators amongst a larger pool of putative suitability indicators, we included only those which were significantly related to the relevant EBPI in block 5 .

Most variables were binary (e.g. no/yes) or continuous (e.g. 0-100); ordinal variables (course of disorder and satisfaction with case manager) were treated as continuous in regression analyses.

Due to reduced sample sizes for satisfaction with a case manager and cognitive functioning variables, these predictors were only used in secondary analyses to avoid limiting the sample for the main analyses.

Each variable was inspected individually for outliers with no differences at the 5\% trimmed mean level beyond the criterion of 0.2 . Hierarchical logistic regression assumptions were met with $>40$ cases per predictor and absence of multi-collinearity (all correlations $<0.5$; tolerance scores $>0.1$ ). In the final model, predictors were identified using $p<0.05$ as a cut-off, with odds ratios and confidence intervals examined. Our criterion for acceptance of a model as useful was set at $25 \%$ better than the chance prediction.
Data analysis was conducted using IBM SPSS for Windows Version 21 (SPSS., 2009).

\section{Results}

Profile of people with psychosis in the Survey of High Impact Psychosis

Survey participants were predominantly single (61.2\%) and male $(59.6 \%)$. Less than one third (31.5\%) had completed the final year of schooling and almost one third $(32.7 \%)$ were in paid employment at some time during the year prior to the interview. Most (63.2\%) had obvious or severe dysfunction in their capacity to socialise over the past year. Almost half had a diagnosis of schizophrenia $(47.0 \%)$ and most had experienced multiple episodes of psychosis with periods of good or partial recovery between (61.5\%) (for a detailed description of the overall sample: Morgan et al. 2012). Table 2 presents demographic, clinical and service characteristics, and suitability indicators for participants.

\section{Receipt of individual EBPIs}

Table 3 presents receipt and eligibility data. Receipt of each intervention was reported by between 12 and $41 \%$ of participants in the past year: up to about one fifth reported an evidence-based level. RPP was the most frequently reported intervention $(41.3 \% ; 21.1 \%$ at evidence-based level) and FPE the least $(11.6 \%$ and $3.4 \%$, respectively). With the exception of ST and RPP, an evidence-based level accounted for less than half of the reported receipt. Applying eligibility indicators (where applicable) made little difference to rates of reported receipt.

\section{Relationships between receipt of individual EBPIs and their putative suitability indicators}

Table 4 presents the suitability indicators for each intervention and the proportion of eligible participants who met each. With the exception of ACT, the 
Table 3. Receipt of any, and evidence-based levels of, psychosocial interventions, including by eligibility

\begin{tabular}{|c|c|c|c|c|c|c|}
\hline \multirow{2}{*}{$\begin{array}{l}\text { Evidence-based } \\
\text { psychosocial intervention (EBPI) }\end{array}$} & \multicolumn{2}{|c|}{ Receipt of any level } & \multicolumn{2}{|c|}{$\begin{array}{c}\text { Receipt of } \\
\text { evidence-based level }^{\mathrm{a}}\end{array}$} & \multicolumn{2}{|c|}{$\begin{array}{l}\text { EBPI receipt by those } \\
\text { eligible }\end{array}$} \\
\hline & $n(\%)$ & Total & $n(\%)$ & Total & $n(\%)$ & Total \\
\hline CBT for psychosis & 407 (22.9) & 1776 & $180(10.1)$ & 1776 & $\mathrm{~N} / \mathrm{A}^{\mathrm{b}}$ & $\mathrm{N} / \mathrm{A}$ \\
\hline Family Psycho-Education & $208(11.6)$ & 1783 & $61(3.4)$ & 1783 & $61(3.6)$ & 1753 \\
\hline Relapse Prevention Planning & $725(41.3)$ & 1755 & $369(21.1)$ & 1746 & $\mathrm{~N} / \mathrm{A}^{\mathrm{b}}$ & N/A \\
\hline Skills Training & $268(15.1)$ & 1777 & $168(9.5)$ & 1777 & $151(10.1)$ & 1502 \\
\hline Supported Employment & $88(15.0)$ & $584^{\mathrm{c}}$ & $41(7.0)$ & 584 & $41(7.0)$ & $584^{\mathrm{c}}$ \\
\hline Assertive Community Treatment & N/A & N/A & $161(8.9)$ & 1802 & $148(8.8)$ & 1678 \\
\hline
\end{tabular}

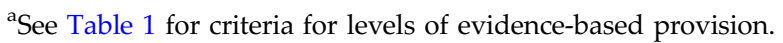

${ }^{\mathrm{b}}$ No eligibility criteria applied for this intervention.

${ }^{\mathrm{c}}$ Receipt of employment support was only asked of those actively looking for work and/or employed during the past year. This matched our identified eligibility criterion of having an employment goal.

proportion meeting each suitability indicator was relatively high, ranging from $18 \%$ with deteriorated relationships due to illness (ST) to $92 \%$ with multiple episodes or continuous illness (RPP). Each EBPI had at least one suitability indicator met by a majority of participants. Associations between each suitability indicator and receipt of the corresponding intervention are reported: three of the six interventions showed associations (CBTp, RPP, ACT). Of 19 suitability indicators tested, five were significantly associated with receipt of the respective EBPI (see Table 4).

\section{Prediction of receipt of one or more EBPIs}

Hierarchical logistic regression was performed to assess the impact of demographic, clinical and service provision characteristics on the likelihood that participants would be in receipt of one or more EBPIs. The full model containing all predictors was statistically significant $\left(\chi^{2}(20, n=1746)=216.12, p<0.01\right)$, indicating that it could differentiate between participants who were, and were not, in receipt of one or more EBPIs. The model explained between $11.6 \%$ (Cox \& Snell R square) and $15.7 \%$ (Nagelkerke $\mathrm{R}$ square) of the variance in group status, correctly classifying $66 \%$ of cases. Entry of demographic variables at block 1 and service provision variables at block 4 improved the model fit (block 1: 1.5\% (Cox and Snell $\mathrm{R}$ square) and $2.0 \%$ (Nagelkerke $\mathrm{R}$ square) of variance explained, $59.8 \%$ correct classification; block 2: $2.1 \%$ (Cox and Snell R square) and 2.9\% (Nagelkerke R square) of variance explained, $60.8 \%$ correct classification; block 3: 2.2\% (Cox and Snell R square) and 3.0\% (Nagelkerke R square) of variance explained, 60.9\% correct classification).
The proportional by chance accuracy rate was $52 \%$. Using the criterion of a $25 \%$ or better prediction beyond chance for model usefulness (i.e. $1.25 \times 52=$ $65 \%$ ), the prediction of $66 \%$ of cases at the final step can be considered useful, albeit marginally.

As shown in Table 5, nine variables made a unique contribution to the model. The strongest predictor of receipt of one or more EBPIs was being assigned a psychologist as a case manager, $\mathrm{OR}(\mathrm{CI})=2.36(1.50$ 3.72). Accessing an NGO in the past year was also a moderately strong predictor: those who had accessed an NGO were twice as likely to have received one or more EBPIs $(\mathrm{OR}(\mathrm{CI})=2.01(1.60-2.51)$ ).

Participants with occupational therapists $(\mathrm{OR}(\mathrm{CI})=$ $1.59(1.08-2.34))$ and nurses $(\mathrm{OR}(\mathrm{CI})=1.25(1.01-1.54))$ as case managers were also more likely to have received one or more EBPIs whereas participants with medical registrars as case managers were less likely to have done so $(\mathrm{OR}(\mathrm{CI})=0.47(0.29-0.74))$.

Despite comprising less than half the sample $(40.5 \%)$, women were $55 \%$ more likely than men to receive an EBPI $(\mathrm{OR}(\mathrm{CI})=1.55(1.27-1.90))$. Participants who had insight about their disorder were more likely to have received one or more EBPIs $(\mathrm{OR}(\mathrm{CI})=1.30$ (1.03-1.65)) as were younger aged clients, compared with older clients $(\mathrm{OR}(\mathrm{CI})=0.99(0.98-0.99))$, albeit very slightly - the chance of receiving an EBPI decreased $1 \%$ for each additional year of age.

Participants who had received treatment via a community treatment order in the past year were slightly more likely to have received one or more EBPIs (OR $(\mathrm{CI})=1.37(1.04-1.79))$.

Secondary analyses showed that satisfaction with case manager was a significant predictor; however, including this variable in the model decreased overall 
Table 4. Suitability indicators for psychosocial interventions and associations with receipt

\begin{tabular}{|c|c|c|c|c|c|}
\hline \multirow[b]{2}{*}{ Suitability indicators for each intervention } & \multicolumn{2}{|c|}{ Suitability indicator met } & \multicolumn{3}{|c|}{ Association with receipt } \\
\hline & $n(\%)$ & Total & $\chi^{2 a}$ & $p$ & Total \\
\hline \multicolumn{6}{|l|}{ CBT for psychosis } \\
\hline Top three challenge of uncontrolled symptoms & $469(25.7)$ & 1825 & 16.39 & 0.000 & 1776 \\
\hline Lack of relief from medication & $635(39.8)$ & 1594 & NS & & \\
\hline Low Carpenter negative syndrome score & $534(29.3)$ & 1825 & NS & & \\
\hline Absence of substance use & $1139(63.0)$ & 1809 & 5.146 & 0.023 & 1764 \\
\hline \multicolumn{6}{|l|}{ Family Psycho-Education } \\
\hline Living with any relative & $851(48.8)$ & 1753 & N/A & & \\
\hline At least weekly face to face family contact & $1343(76.6)$ & 1753 & N/A & & \\
\hline Composite indicator ${ }^{\mathrm{b}}$ & $839(47.9)$ & 1753 & NS & & \\
\hline \multicolumn{6}{|l|}{ Relapse Prevention Planning } \\
\hline Any mental health admission past year & $626(34.6)$ & 1809 & 17.63 & 0.000 & 1745 \\
\hline Multiple episodes or continuous illness ${ }^{c}$ & $1678(91.9)$ & 1825 & NS & & \\
\hline \multicolumn{6}{|l|}{ Skills Training } \\
\hline Illness interferes with desired relationships & $574(39.5)$ & 1452 & NS & & \\
\hline Dysfunction in overall socialising & $1031(68.7)$ & 1501 & NS & & \\
\hline Relationships deteriorated due to illness & $261(17.6)$ & 1484 & NS & & \\
\hline Poorer independent living role performance & $592(32.4)$ & 1825 & 3.02 & 0.082 & 1777 \\
\hline \multicolumn{6}{|l|}{ Supported Employment } \\
\hline Wanted help to work or use time & $175(22.2)$ & 787 & NS & & \\
\hline Post-school qualification & $443(56.3)$ & 787 & NS & & \\
\hline \multicolumn{6}{|l|}{ Assertive Community Treatment } \\
\hline Poor functioning $(\mathrm{PSP}<31)$ & $89(5.3)$ & 1678 & 4.28 & 0.039 & 1658 \\
\hline Very unconfident medication a good thing & $87(5.4)$ & 1612 & 2.94 & 0.086 & 1515 \\
\hline Multiple episodes with partial recovery or continuous illness ${ }^{c}$ & $1136(62.2)$ & 1678 & NS & & \\
\hline Two or more admissions in past year & $213(12.7)$ & 1678 & 16.935 & 0.000 & 1658 \\
\hline Any substance use in past year & $616(36.7)$ & 1678 & NS & & \\
\hline Very dissatisfied with case manager support & $38(3.6)$ & 1058 & 3.75 & 0.053 & 1058 \\
\hline
\end{tabular}

${ }^{\mathrm{a}} \chi^{2}$ results reported where $p<0.10(\mathrm{df}=2)$.

${ }^{b}$ met 'living with any relative' and 'at least weekly face to face contact'.

${ }^{c}$ These aspects of course of disorder were rated by the interviewers based on the entire interview.

prediction because of the associated reduction in sample size. The cognitive variables (DSCT and NART) were also examined in an additional analysis, however, were not found to be significant predictors.

Given the nature of ACT as a service type rather than a discrete psychosocial intervention as were the other EBPIs, we re-ran the model excluding ACT. The overall level of prediction improved slightly (67.8\% of cases compared with $66 \%$ ) although $\mathrm{R}^{2}$ estimates reduced. The predictors remained unchanged except for 'case manager - nurse' and 'community treatment order in the past year', which were no longer statistically significant.

\section{Prediction of individual EBPIs}

Although the equations for all but FPE were statistically significant, none met the $25 \%$ greater than chance criterion and the amount of variance explained was low (Table 6). Depending on the method, the variance explained ranged from 1.7\% for FPE (Cox and Snell R square) to $17.6 \%$ for $\mathrm{SE}$ (Nagelkerke $\mathrm{R}$ square) (Table 6). Significant predictors varied across interventions. For example, predictors of receipt of ST were: not being in a marital/de facto relationship; the presence of insight; accessed NGO in past year; treatment via CTO in past year; and having an OT as a case manager. Whereas, for receipt of SE, predictors were: completed Year 12 education; the better course of disorder; and, accessed NGO in past year (see Table 6). Apart from insight, which was associated with a greater likelihood of receipt of CBTp, RPP and ST and a lesser likelihood of receipt of $\mathrm{ACT}$, no demographic, clinical or service characteristic was significant for more than three of the six EBPIs. Each of the suitability indicators identified previously as being associated with an intervention was confirmed as a significant predictor when added in the last block (that is, uncontrolled symptoms 
Table 5. Hierarchical logistic regression: Receipt of one or more evidence-based psychosocial interventions v. no evidence-based psychosocial interventions received $(n=1746)$

\begin{tabular}{|c|c|c|c|c|c|}
\hline Predictor & B & S.E. & $p$ & OR & $\mathrm{CI}(\mathrm{L}, \mathrm{U})$ \\
\hline \multicolumn{6}{|l|}{ Block 0} \\
\hline Constant & -0.40 & 0.05 & $<0.01$ & 0.67 & \\
\hline \multicolumn{6}{|l|}{ Block 1} \\
\hline Sex (male/female) & 0.44 & 0.13 & $<0.01$ & 1.55 & $1.27-1.90$ \\
\hline Age (18-65) & -0.01 & 0.01 & $<0.01$ & 0.99 & $0.98-0.99$ \\
\hline In a marital/de facto relationship (no/yes) & -0.08 & 0.13 & 0.53 & 0.92 & $0.71-1.20$ \\
\hline Completed Year 12 (no/yes) & 0.05 & 0.11 & 0.62 & 1.01 & $0.86-1.30$ \\
\hline First Language English (no/yes) & -0.17 & 0.18 & 0.35 & 0.81 & $0.58-1.15$ \\
\hline Constant & -0.09 & 0.19 & 0.63 & 0.91 & \\
\hline \multicolumn{6}{|l|}{ Block 2} \\
\hline Personal and Social Performance (PSP) score (0-100) & 0.00 & 0.00 & 0.48 & 0.00 & $0.99-1.00$ \\
\hline Course of disorder ${ }^{\mathrm{a}}$ & 0.08 & 0.05 & 0.10 & 0.08 & $0.99-1.19$ \\
\hline Insight about disorder (no/yes) & -0.26 & 0.12 & 0.03 & 1.30 & $1.03-1.65$ \\
\hline Lifetime alcohol abuse/dependence (no/yes) & -0.02 & 0.11 & 0.87 & 0.98 & $0.79-1.23$ \\
\hline Lifetime other substance abuse/dependence (no/yes) & -0.18 & 0.12 & 0.13 & 0.84 & $0.67-1.06$ \\
\hline Type of psychosis (non-affective/affective) & 0.10 & 0.11 & 0.33 & 0.11 & $0.90-1.37$ \\
\hline Constant & 0.13 & 0.36 & 0.71 & 0.14 & \\
\hline \multicolumn{6}{|l|}{ Block 3} \\
\hline Any positive symptoms in past $4-6$ weeks (no/yes) & 0.02 & 0.11 & 0.87 & 1.02 & $0.82-1.26$ \\
\hline Carpenter negative syndrome score (0-6) & 0.03 & 0.03 & 0.33 & 1.03 & $0.97-1.09$ \\
\hline Constant & 0.00 & 0.38 & 0.99 & 1.00 & \\
\hline \multicolumn{6}{|l|}{ Block 4 (final) } \\
\hline Accessed NGO in past year (no/yes) & 0.70 & 0.11 & $<0.01$ & 2.01 & $1.60-2.51$ \\
\hline Community treatment order in past year (no/yes) & 0.31 & 0.14 & 0.02 & 1.37 & $1.04-1.79$ \\
\hline Case manager - medical registrar (no/yes) & -0.76 & 0.24 & $<0.01$ & 0.47 & $0.29-0.74$ \\
\hline Case manager - nurse (no/yes) & 0.22 & 0.11 & 0.04 & 1.25 & $1.01-1.54$ \\
\hline Case manager - psychologist (no/yes) & 0.86 & 0.23 & $<0.01$ & 2.36 & $1.50-3.72$ \\
\hline Case manager - social worker (no/yes) & 0.16 & 0.13 & 0.21 & 1.17 & $0.92-1.50$ \\
\hline Case manager - occupational therapist (no/yes) & 0.47 & 0.20 & 0.02 & 1.59 & $1.08-2.34$ \\
\hline Constant & -0.14 & 0.41 & 0.73 & 0.87 & \\
\hline
\end{tabular}

Evidence-based psychosocial interventions: CBT for psychosis, Family Psycho-Education, Relapse Prevention Planning, Skills Training, Supported Employment, Assertive Community Treatment.

Bold indicates a significant $p$ value of $<0.05$.

a single episode with good recovery; multiple episodes with good recovery; multiple episodes with partial recovery; continuous, chronic illness; continuous, chronic illness with deterioration.

as a top three challenge in the next year as a predictor of receipt of CBTp, any mental health admission in the past year for RPP, and two or more admissions in the past year for ACT). The strongest service predictor, and the strongest identified predictor overall was having a psychologist as case manager: this was associated with four times the likelihood of receiving CBTp.

\section{Discussion}

People living with psychosis reported limited receipt of EBPIs during a year of treatment in specialist mental health services: fewer than half received each intervention and less than one-fifth received an evidence-based level. This includes RPP, which might be assumed to be frequently indicated and routinely available in this setting, and FPE which, although recommended by CPGs in Australia since 1984, was reported at an evidence-based level by fewer than $4 \%$. Ineligibility did not explain this limited receipt. We found only patchy evidence for targeting of psychosocial interventions to those who might benefit most; less than one-quarter of suitability indicators were associated with receipt of the relevant EBPI, suggesting that targeting or uptake was largely due to other factors. Our model predicted receipt of one or more EBPIs, correctly classifying $66 \%$ of participants. Interestingly, clinical predictors, such as symptomatology, had little predictive value, whereas service provision 
Table 6. Hierarchical logistic regression models for receipt of each evidence-based psychosocial intervention with odds ratios for predictors significant at $p<0.05$, and model statistics

\begin{tabular}{|c|c|c|c|c|c|c|}
\hline Predictor & $\begin{array}{l}\text { CBT for } \\
\text { psychosis } \\
(n=1403)\end{array}$ & $\begin{array}{l}\text { Family Psycho- } \\
\text { Education } \\
(n=1660)\end{array}$ & $\begin{array}{c}\text { Relapse Prevention } \\
\text { Planning } \\
(n=1691)\end{array}$ & $\begin{array}{l}\text { Skills Training } \\
\quad(n=1412)\end{array}$ & $\begin{array}{l}\text { Supported } \\
\text { Employment } \\
\quad(n=748)\end{array}$ & $\begin{array}{c}\text { Assertive } \\
\text { Community } \\
\text { Treatment } \\
(n=1636)\end{array}$ \\
\hline \multicolumn{7}{|l|}{ Demographic characteristics } \\
\hline Sex (male/female) & $2.21(1.60-3.05)$ & - & $1.43(1.12-1.82)$ & - & - & - \\
\hline Age (18-65) & - & - & $0.98(0.97-0.99)$ & - & - & - \\
\hline In a marital/de facto relationship (n/y) & - & - & - & $0.47(0.25-0.89)$ & - & - \\
\hline Completed Year $12(\mathrm{n} / \mathrm{y})$ & $1.60(1.16-2.21)$ & - & - & - & $3.26(1.64-6.49)$ & - \\
\hline First Language English (n/y) & - & - & - & - & - & - \\
\hline \multicolumn{7}{|l|}{ Clinical characteristics } \\
\hline Personal and Social Performance (PSP) Score $(0-100)^{a}$ & $1.01(1.00-1.03)$ & - & - & - & - & $0.97(0.96-0.99)$ \\
\hline Course of disorder ${ }^{\mathrm{b}}$ & $1.27(1.08-1.50)$ & - & - & - & $1.45(1.04-2.02)$ & $0.79(0.65-0.95)$ \\
\hline Insight about disorder (n/y) & $2.27(1.31-3.95)$ & - & $1.44(1.07-1.96)$ & $1.81(1.16-2.82)$ & - & $0.65(0.44-0.95)$ \\
\hline Lifetime alcohol abuse/dependence (n/y) & $1.47(1.01-2.13)$ & - & - & - & - & - \\
\hline Lifetime other substance abuse/dependence (n/y) & $0.55(0.38-0.81)$ & - & - & - & - & - \\
\hline Type of psychosis (non-affective/affective) & $2.51(1.79-3.52)$ & - & - & - & - & - \\
\hline Any positive symptoms past $4-6$ weeks (n/y) & - & - & - & - & - & - \\
\hline Carpenter negative syndrome score $(0-6)$ & - & - & $0.91(0.84-0.98)$ & - & - & $1.14(1.02-1.26)$ \\
\hline \multicolumn{7}{|l|}{ Service characteristics } \\
\hline $\begin{array}{l}\text { Accessed Non-Government Organisation } \\
(\mathrm{NGO}) \text { in past year }(\mathrm{n} / \mathrm{y})\end{array}$ & - & - & $1.69(1.30-2.20)$ & $2.16(1.51-3.09)$ & $3.03(1.49-6.18)$ & - \\
\hline Community treatment order in past year $(n / y)$ & - & - & $1.40(1.03-1.90)$ & $2.58(1.42-4.70)$ & - & $2.64(1.79-3.87)$ \\
\hline Case manager - medical registrar (n/y) & $0.36(0.13-0.99)$ & - & $0.54(0.29-0.98)$ & - & - & $\mathrm{n} / \mathrm{a}^{\mathrm{c}}$ \\
\hline Case manager - nurse $(n / y)$ & - & $2.03(1.11-3.72)$ & $1.36(1.06-1.74)$ & - & - & $\mathrm{n} / \mathrm{a}^{\mathrm{c}}$ \\
\hline Case manager - psychologist (n/y) & $4.39(2.65-7.26)$ & - & $1.85(1.18-2.90)$ & - & - & $\mathrm{n} / \mathrm{a}^{\mathrm{c}}$ \\
\hline Case manager - social worker (n/y) & - & $2.06(1.07-3.97)$ & $1.43(1.08-1.88)$ & - & - & $\mathrm{n} / \mathrm{a}^{\mathrm{c}}$ \\
\hline Case manager - occupational therapist (n/y) & - & - & - & $1.69(1.01-2.81)$ & - & $\mathrm{n} / \mathrm{a}^{\mathrm{c}}$ \\
\hline \multicolumn{7}{|l|}{ Suitability indicators ${ }^{\mathrm{a}}$} \\
\hline Two or more admissions past year $(\mathrm{n} / \mathrm{y})$ & $\mathrm{n} / \mathrm{a}$ & $\mathrm{n} / \mathrm{a}$ & $\mathrm{n} / \mathrm{a}$ & $\mathrm{n} / \mathrm{a}$ & $\mathrm{n} / \mathrm{a}$ & $1.78(1.14-2.77)$ \\
\hline Top 3 challenge of uncontrolled symptoms (n/y) & $1.48(1.03-2.13)$ & $\mathrm{n} / \mathrm{a}$ & $\mathrm{n} / \mathrm{a}$ & $\mathrm{n} / \mathrm{a}$ & $\mathrm{n} / \mathrm{a}$ & $\mathrm{n} / \mathrm{a}$ \\
\hline Any admission past year $(\mathrm{n} / \mathrm{y})$ & $\mathrm{n} / \mathrm{a}$ & $\mathrm{n} / \mathrm{a}$ & $1.40(1.07-1.82)$ & $\mathrm{n} / \mathrm{a}$ & $\mathrm{n} / \mathrm{a}$ & $\mathrm{n} / \mathrm{a}$ \\
\hline \multicolumn{7}{|l|}{ Model statistics } \\
\hline$\chi^{2}(d f, p)$ & $145.82(22,<0.001)$ & $29.10(20,0.09)$ & $135.07(21,<0.001)$ & $80.38(20,<0.001)$ & $45.54(20,0.001)$ & $79.44(16,<0.001)$ \\
\hline Variance explained & $8.2 \%, 16.9 \%$ & $1.7 \%, 6.5 \%$ & $7.7 \%, 12.0 \%$ & $5.5 \%, 11.2 \%$ & $5.9 \%, 17.6 \%$ & $4.7 \%, 10.5 \%$ \\
\hline
\end{tabular}

aPoor functioning (PSP) was a statistically significant univariate suitability indicator for Assertive Community Treatment, but PSP score was included in each of these models in step 2 (clinical characteristics) rather than step 4 as it was hypothesised to be a broad clinical predictor.

${ }^{\mathrm{b}}$ Single episode with good recovery; multiple episodes with good recovery; multiple episodes with partial recovery; continuous, chronic illness; continuous, chronic illness with deterioration.

${ }^{\mathrm{c}}$ Current case manager cannot be a predictor of entry to current service. 
characteristics - accessing a non-clinical mental health support service (NGO), being on an involuntary community treatment order and the case manager's profession - made the greatest contribution to prediction. This reinforces other research demonstrating the influence of service characteristics on the delivery of EBPIs (Magliano et al. 2006). This suggests that the evidence for clinical factors predicting outcomes (Granholm et al. 2008; Thomas et al. 2011; Kortrijk et al. 2012) may be overlooked in decisions about providing EBPIs to people with psychosis.

Previous reports of limited receipt of EBPIs by people with psychosis are reinforced (Bond et al. 2000; Killackey et al. 2008; Prytys et al. 2011; Harris \& Boyce, 2013; Haddock et al. 2014). Interventions to improve relationships (FPE, ST) were rarely reported and apparently poorly targeted, suggesting multiple barriers to their implementation should be considered, including organisational factors and negative staff attitudes (Haddock et al. 2014; Ince et al. 2016; Magliano et al. 2017). Reported receipt of SE was also low, perhaps reflecting the poor integration of employment and mental health supports in Australia (Killackey \& Waghorn, 2008).

In contrast, receipt of ACT (8.9\%) was similar to that reported in a US study of veterans $(7 \%$, McCarthy et al. 2009), with evidence of targeting to those likely to be at risk for hospitalisation. Several explanations are possible: ACT is a well-defined intervention with clear fidelity criteria (Monroe-DeVita et al. 2011); teambased interventions, such as ACT, may be easier to implement and sustain; and, ACT has been subject to more systematic implementation efforts in Australia (Harvey et al. 2012; Monroe-DeVita et al. 2012). Thus, ACT implementation may provide useful lessons for the implementation of other EBPIs.

Suitability is a complex notion. Current recommendations, such as for FPE (Galletly et al. 2016) and CBTp (NICE, 2014), are widely inclusive; yet it seems likely that some subgroups may not accept, and not all may benefit from, these interventions (Barrowclough et al. 2010; Klingberg et al. 2011; Thomas et al. 2011). Research has not addressed the ideal proportion of people with psychosis who should receive each intervention, making evidence-practice gaps difficult to quantify. Further, the RCTs generating efficacy data are typically underpowered to examine outcome predictors (Menon et al. 2015). Future studies predicting outcome and suitability may prompt better targeting of interventions such as tailoring CBTp for ethnic minorities (Rathod et al. 2013).

Having a psychologist as a case manager was the strongest predictor of receipt of one or more EBPIs, and also strongly predicted receipt of CBTp and RPP in the individual regressions. Psychologists are trained as 'scientist-practitioners' (McDermott et al. 2012), likely resulting in awareness of, and skills to deliver, EBPIs. Although negative attitudes to the implementation of psychosocial interventions amongst practitioners, including psychologists, have been reported (Ince et al. 2016; Magliano et al. 2017), this is not a uniform finding. It is possible that the relatively few psychologists who seek to work with people experiencing psychosis in Australia represent a subgroup with more positive attitudes. Linked with this, psychologists may be especially likely to seek to work with, or be allocated to, patients who might be more easily engaged in EBPIs in services where allocations take account of professional interests and skills. It is also possible that the choice of case manager reflects the fact that the patient is already in receipt of therapy delivered by a particular professional, although we were unable to further explore any of these possibilities. By contrast, patients perceived to have few psychosocial needs may be allocated to medical case managers in services where the medical role has a narrower biomedical focus. A less generous interpretation is that although the role of case manager includes ensuring that EBPIs are offered on the basis of consumer needs, case managers' comfort or familiarity with EBPIs may lead to favouring interventions related to their own profession. Profession-specific biases potentially detract from optimal treatment.

Our regression models predicting receipt of individual EBPIs were statistically significant for all but FPE; however, the variance explained was small. Nonetheless, they confirmed the relevance of the selected suitability indicators for individual EBPIs and may provide clues to factors that influence receipt. Receipt of RPP, ST and SE were each associated with having accessed an NGO. This appears consistent with these services' focus on wellness promotion, practical support for recovery and community re-integration. Better insight was positively associated with CBTp, RPP and ST suggesting that a degree of insight may be required for interventions fostering self-management and skills.

\section{Strengths and limitations of the study}

To our knowledge, this is the first study using epidemiological data to examine receipt of EBPIs by people living with psychosis. Strengths include the use of the large representative sample from the Australian national survey and its suite of variables for modelling purposes. Nonetheless, the study has a number of limitations. Our choice of a 'least exclusionary' eligibility criterion for each EBPI was intended to prioritise awareness of lack of receipt of each EBPI for all who 
could benefit. However, this may have been at the expense of over-estimating the number eligible. Some suitability indicators noted in the relatively sparse literature were not available for these analyses or were approximations. The study should be regarded as exploratory, therefore, especially since data are crosssectional. There are also 'common elements' shared by some of these psychosocial interventions (e.g. identification and monitoring of individual Early Warning Signs of relapse is included in some FPE models, as well as being central to RPP) (Chorpita et al. 2007). Therefore, we cannot rule out the possibility of partial overlap between those psychosocial interventions in data collection. The study design also did not allow us to explore whether the psychosocial interventions were considered, offered and refused or not offered by case managers. Building on Haddock et al.'s (2014) small study would be valuable. This limitation is also being addressed in a small sub-study currently being prepared for submission. Similar to other studies relying on reports of provision (e.g. West et al. 2005), our data were reliant on participant self-report and therefore subject to recall bias. This may have led to underestimating receipt if the description of the intervention was not recognised by the participant; an overestimate of evidence-based receipt is also plausible, considering we were unable to assess intervention quality.

\section{Conclusions}

Australians living with psychoses report receipt of EBPIs, but with the exception of the ACT, at lower levels than recommended by evidence-based CPGs, and relatively unrelated to eligibility and suitability indicators. Greater implementation effort and better targeting are likely required. Recognised implementation strategies might be usefully drawn upon (Monroe-DeVita et al. 2012). These include policies which define program standards and build in contingencies and incentives for implementation of psychosocial interventions. Education, training and consultation are also essential to strengthen evidencebased practice literacy in the professions, particularly those other than psychologists, to guide individual service planning (Harris \& Boyce, 2013; Magliano et al. 2017). Needs-based system re-design may also be needed (Harris \& Boyce, 2013; Ince et al. 2016), drawing upon characteristics of mental health service systems that effectively implement evidence-based interventions. The study highlights how little we know about receipt, targeting and benefits of EBPI provision. Future research should model a better-targeted service delivery system taking account of patient needs over time (McGorry et al. 2006), and the relative benefit and opportunity costs from EBPI provision (Pandiani et al. 2004).

\section{Acknowledgements}

This publication is based on data collected in the framework of the 2010 Australian National Survey of High Impact Psychosis. In 2010, the members of the Survey of High Impact Psychosis Study Group were: V. Morgan (National Project Director), A. Jablensky (Chief Scientific Advisor), A. Waterreus (National Project Coordinator), R. Bush, V. Carr, D. Castle, M. Cohen, C. Galletly, C. Harvey, B. Hocking, A. Mackinnon, P. McGorry, J. McGrath, A. Neil, S. Saw, H. Stain. This report acknowledges, with thanks, the hundreds of mental health professionals who participated in the preparation and conduct of the survey and the many Australians with psychotic disorders who gave their time and whose responses form the basis of this publication.

\section{Financial support}

The study was funded by the Australian Government Department of Health and Ageing.

\section{Conflicts of interest}

None.

\section{Ethical standards}

The study was approved by institutional human research ethics committees at each site. All participants provided written informed consent.

\section{Availability of data and materials}

Access to the data and materials on which this study is based is authorised through the SHIP Access and Publication Committee. The Committee Convenor is Professor Vera Morgan (vera.morgan@uwa.edu.au) and Executive Officer is Assistant Professor Anna Waterreus (anna.waterreus@uwa.edu.au).

\section{References}

Aagaard J, Muller-Nielsen K (2011). Clinical outcome of assertive community treatment (ACT) in a rural area in Denmark: a case-control study with a 2-year follow-up. Nordic Journal of Psychiatry 65, 299-305.

Agius M, Shah S, Ramkisson R, Murphy S, Zaman R (2007). Three year outcomes of an early intervention for psychosis service as compared with treatment as usual for 
first psychotic episodes in a standard community mental health team - final results. Psychiatria Danubina 19, 130-138.

Alvarez-Jimenez M, Priede A, Hetrick S, Bendall S, Killackey E, Parker A, McGorry P, Gleeson J (2012). Risk factors for relapse following treatment for first episode psychosis: a systematic review and meta-analysis of longitudinal studies. Schizophrenia Research 139, 116-128.

Barrowclough C, Haddock G, Wykes T, Beardmore R, Conrod P, Craig T, Davies L, Dunn G, Eisner E, Lewis S, Moring J, Steel C, Tarrier N (2010). Integrated motivational interviewing and cognitive behavioural therapy for people with psychosis and comorbid substance misuse: randomised controlled trial. BMJ 341, c6325.

Bond G (2004). Supported employment: evidence for an evidence-based practice. Psychiatric Rehabilitation Journal 27, 345-359.

Bond G, Becker D, Drake R, Rapp C, Meisler N, Lehman A, Bell M, Blyler C (2000). Implementing supported employment as an evidence-based practice. Psychiatric Services 52, 313-322.

Brugha T, Taub N, Smith J, Morgan Z, Hill T, Meltzer H, Wright C, Burns T, Priebe S, Evans J, Fryers T (2012). Predicting outcome of assertive outreach across England. Social Psychiatry and Psychiatric Epidemiology 47, 313-322.

Campbell K, Bond G, Drake R, McHugo G, Xie H (2010). Client predictors of employment outcomes in high-fidelity supported employment. Journal of Nervous and Mental Disease 198, 556-563.

Castle D, Jablensky A, McGrath J, Carr V, Morgan V, Waterreus A, Valuri G, Stain H, McGuffin P, Farmer A (2006). The diagnostic interview for psychoses (DIP): development, reliability and applications. Psychological Medicine 36, 69-80.

Chorpita B, Becker K, Daleiden E (2007). Understanding the common elements of evidence-based practice: misconceptions and clinical examples. American Academy of Child and Adolescent Psychiatry 46, 647-652.

Cuddeback G, Morrissey J, Meyer P (2006). How many assertive community treatment teams do we need? Psychiatric Services 57, 1803-1806.

Dixon L (2000). Assertive community treatment: twenty-five years of gold. Psychiatric Services 51, 759-765.

Dixon L, Dickerson F, Bellack A, Bennett M, Dickinson D, Goldberg R, Lehman A, Tenhula W, Calmes C, Pasillas R, Peer J, Kreyenbuhl J (2010). The 2009 schizophrenia PORT psychosocial treatment recommendations and summary statements. Schizophrenia Bulletin 36, 48-70.

Fadden G, Birchwood M, Lefley H, Johnson D (2002). British models for expanding family psychoeducation in routine practice. In Family Interventions in Mental Illness: International Perspectives (ed. H. Lefley and D. Johnson), pp. 25-42. Praeger Publishers: USA.

Fanning J, Bell M, Fiszdon J (2012). Is it possible to have impaired neurocognition but good social cognition in schizophrenia? Schizophrenia Research 135, 68-71.

Galletly C, Castle D, Dark F, Humberstone V, Jablensky A, Killackey E, Kulkarni J, McGorry P, Nielssen O, Tran N
(2016). Royal Australian and New Zealand college of psychiatrists: clinical practice guidelines for the management of schizophrenia and related disorders. Australia and New Zealand Journal of Psychiatry 50, 410-472.

Garety P, Fowler D, Freeman D, Bebbington P, Dunn G, Kuipers E (2008). Cognitive-behavioural therapy and family intervention for relapse prevention and symptom reduction in psychosis: randomised controlled trial. British Journal of Psychiatry 192, 412-423.

Granholm E, McQuaid J, Link P, Fish S, Patterson T, Jeste D (2008). Neuropsychological predictors of functional outcome in cognitive behavioral social skills training for older people with schizophrenia. Schizophrenia Research 100, 133-143.

Gumley A, O'Grady M, McNay L, Reilly J, Power K, Norrie J (2003). Early intervention for relapse in schizophrenia: results of a 12-month randomized controlled trial of cognitive behavioural therapy. Psychological Medicine 33, 419-431.

Haddock G, Eisner E, Boone C, Davies G, Coogan C, Barrowclough C (2014). An investigation of the implementation of NICE-recommended CBT interventions for people with schizophrenia. Journal of Mental Health 23, 162-165.

Harris A, Boyce P (2013). Why do we not use psychosocial interventions in the treatment of schizophrenia? Australian and New Zealand Journal of Psychiatry 47, 501-504.

Harvey C, Killaspy H, Martino S, Johnson S (2012). Implementation of assertive community treatment in Australia: model fidelity, patient characteristics and staff experiences. Community Mental Health Journal 48, 652661.

Harvey C, Brophy L, Parsons S, Moeller-Saxone K, Grigg M, Siskind D (2016). People living with psychosocial disability: rehabilitation and recovery-informed service provision within the second Australian national survey of psychosis. Australia and New Zealand Journal of Psychiatry 50, 534-547.

Herz M, Lambert J, Mintz J, Scott R, O'Dell S, Cartan L, Nix G (2000). A program of relapse prevention in schizophrenia. A controlled study. Archives in General Psychiatry 57, 277-283.

Ince P, Haddock G, Tai S (2016). A systematic review of the implementation of recommended psychological interventions for schizophrenia: rates, barriers, and improvement strategies. Psychology and Psychotherapy 89, 324-350.

Jablensky A, McGrath J, Herrman H, Castle D, Gureje O, Evans M, Carr V, Morgan V, Korten A, Harvey C (2000). Psychotic disorders in urban areas: an overview of the study on low prevalence disorders. Australian and New Zealand Journal of Psychiatry 34, 221-236.

Killackey E, Waghorn G (2008). The challenge of integrating employment services with public mental health services in Australia: progress at the first demonstration site. Psychiatric Rehabilitation Journal 32, 63-66.

Killackey E, Jorm A, Alvarez-Jimenez M, McCann TV, Hides L, Couineau AL (2008). Do we do what we know 
works, and if not why not? Australia and New Zealand Journal of Psychiatry 42, 439-444.

Killackey E, Harvey C, Amering M, Herrman H (2015). Partnerships for meaningful community living: rehabilitation and recovery-informed practices. In Psychiatry (ed. A. Tasman, J. Kay, J. Lieberman, M. First and M. Riba), pp. 1959-1982. John Wiley and Sons Ltd.: Chichester, UK.

Kim H, Salyer M (2008). Attitudes and perceived barriers to working with families of persons with severe mental illness: mental health professionals' perspective. Community Mental Health Journal 44, 337-345.

Kirkpatrick B, Buchanan R, McKenney P, Alphs L, Carpenter W (1989). The schedule for the deficit syndrome: an instrument for research in schizophrenia. Psychiatry Research 30, 119-123.

Klingberg S, Wolwer W, Engel C, Wittorf A, Herrlich J, Meisner C, Buchkremer G, Wiedemann G (2011). Negative symptoms of schizophrenia as primary target of cognitive behavioral therapy: results of the randomized clinical TONES study. Schizophrenia Bulletin 37, S98-S110.

Kortrijk H, Mulder C, Drukker M, Wiersma D,

Duivenvoorden H (2012). Duration of assertive community treatment and the interpretation of routine outcome data. Australia and New Zealand Journal of Psychiatry 46, 240-248.

Lehman A, Steinwachs D (1998). Translating research into practice: the schizophrenia patient outcomes research team (PORT) treatment recommendations. Schizophrenia Bulletin 24, 1-10.

Lehman A, Kreyenbuhl J, Buchanan R, Dickerson F, Dixon LB, Goldberg R, Green-Paden L, Tenhula W, Boerescu D, Tek C, Sandson N, Steinwachs D (2004). The schizophrenia patient outcomes research team (PORT): updated treatment recommendations 2003. Schizophrenia Bulletin 30, 193-217.

Magliano L, Fadden G, Economou M, Xavier M, Held T, Guarneri M, Marasco C, Tosini P, Maj M (1998). Social and clinical factors influencing the choice of coping strategies in relatives of patients with schizophrenia: results of the BIOMED I study. Social Psychiatry and Psychiatric Epidemiology 33, 413-419.

Magliano L, Fiorillo A, Malangone C, De Rosa C, Maj M, Family Intervention Working Group (2006). Implementing psychoeducational interventions in Italy for patients with schizophrenia and their families. Psychiatric Services 57, 266-269.

Magliano L, Read J, Affuso G (2017). Predictors of staff attitudes toward schizophrenia treatments. Psychiatric Services 68, 1321.

Major B, Hinton F, Flint A, Chalmers-Brown A, McLoughlin K, Johnson S (2010). Evidence of the effectiveness of a specialist vocational intervention following first episode psychosis: a naturalistic prospective cohort study. Social Psychiatry and Psychiatric Epidemiology 45, 1-8.

McCarthy J, Valenstein M, Dixon L, Visnic S, Blow F, Slade E (2009). Initiation of assertive community treatment among veterans with serious mental illness: client and program factors. Psychiatric Services 60, 196-201.

McDermott F, Huppert D, Blashi G, Stone L, Epstein M, Olsen A, Elsom S, Meadows G, Rosen A, Singh B, Ash D,
Turnball C, Bland R, Fossey E, Farhall J, Tsismetsi A, Nagel T, Minas H, Clarke M, Leggatt M, Cavill M (2012). The active participants in mental health services. In Mental Health in Australia: Collaborative Community Practice (ed. G. Meadows, J. Farhall, E. Fossey, M. Grigg, F. McDermott and B. Singh), pp. 267-318. Oxford University Press: South Melbourne.

McGorry P, Hickie I, Yung A, Pantelis C, Jackson H (2006). Clinical staging of psychiatric disorders: a heuristic framework for choosing earlier, safer and more effective interventions. Australia and New Zealand Journal of Psychiatry 40, 616-622.

McHugo G, Drake R, Whitley R, Bond G, Campbell K, Rapp C, Goldman H, Lutz W, Finnerty M (2007). Fidelity outcomes in the national implementing evidence-based practices project. Psychiatric Services 58, 1279-1284.

Menon M, Andersen D, Quilty L, Woodward T (2015). Individual factors predicted to influence outcome in group CBT for psychosis (CBTp) and related therapies. Frontiers in Psychology 6, Article 1563. doi: 10.3389/fpsyg.2015.01563.

Monroe-DeVita M, Teague G, Moser L (2011). The TMACT: a new tool for measuring fidelity to assertive community treatment. Journal of American Psychiatric Nurses Association 17, 17-29.

Monroe-DeVita M, Morse G, Bond G (2012). Program fidelity and beyond: multiple strategies and criteria for ensuring quality of assertive community treatment. Psychiatric Services 63, 743-750.

Morgan A, Waterreus A, Jablensky A, Mackinnon A, McGrath J, Carr V, Bush R, Castle D, Cohen M, Harvey C, Galletly C, Stain H, Neil A, McGorry P, Hocking B, Shah S, Saw S (2012). People living with psychotic illness in 2010: the second Australian national survey of psychosis. Australia and New Zealand Journal of Psychiatry 46, 735-752.

Morosini P, Magliano L, Brambilla L, Ugolini S, Pioli R (2000). Development, reliability and acceptability of a new version of the DSM-IV Social and Occupational Functioning Assessment Scale (SOFAS) to assess routine social functioning. Acta Psychiatrica Scandinavica 101, 323-329.

Nelson H, Willison J (1991). The Revised National Adult Reading Test - Test Manual. NFER-Nelson: Windsor, UK.

NICE (2014). Psychosis and Schizophrenia in Adults: Prevention and Management. Clinical Guideline. National Institute for Health and Care Excellence: UK.

Pandiani J, Simon M, Tracy B, Banks S (2004). Impact of multi-agency employment services on employment rates. Community Mental Health Journal 40, 333-345.

Prytys M, Garety P, Jolley S, Onwumere J, Craig T (2011). Implementing the NICE guideline for schizophrenia recommendations for psychological therapies: a qualitative analysis of the attitudes of CMHT staff. Clinical Psychology and Psychotherapy 18, 48-59.

Randolph C, Tierney M, Mohr E, Chase T (1998). The repeatable battery for the assessment of neuropsychological status (RBANS): preliminary clinical validity. Journal of Clinical and Experimental Neuropsychology 20, 310-319. 
Rathod S, Phiri P, Harris S, Underwood C, Thagadur M, Padmanabi U, Kingdon D (2013). Cognitive behaviour therapy for psychosis can be adapted for minority ethnic groups: a randomised controlled trial. Schizophrenia Research 143, 319-326.

Silverstein S, Hatashita-Wong M, Solak BA, Uhlhaas $P$, Landa Y, Wilkniss S, Goicochea C, Carpiniello K,

Schenkel L, Savitz A, Smith T (2005). Effectiveness of a two-phase cognitive rehabilitation intervention for severely impaired schizophrenia patients. Psychological Medicine 35, 829-837.

Sivec H, Montesano V (2012). Cognitive behavioral therapy for psychosis in clinical practice. Psychotherapy 49, 258-270.

SPSS. (2009). SPSS for Windows, Version 19. SPSS Inc.: Chicago.

Thomas N, Rossell S, Farhall J, Shawyer F, Castle D (2011). Cognitive behavioural therapy for auditory hallucinations: effectiveness and predictors of outcome in a specialist clinic. Behavioral and Cognitive Psychotherapy 39, 129-138.

Ucok A, Cakir S, Duman ZC, Discigil A, Kandemir P, Atli H (2006). Cognitive predictors of skill acquisition on social problem solving in patients with schizophrenia. European Archives of Psychiatry and Clinical Neuroscience 256, 388-394.

van der Gaag M, Stant A, Wolters K, Buskens E, Wiersma D (2011). Cognitive-behavioural therapy for persistent and recurrent psychosis in people with schizophrenia-spectrum disorder: cost-effectiveness analysis. British Journal of Psychiatry 198, S59-S65.

West J, Wilk J, Olfson M, Rae D, Marcus S, Narrow W, Pincus H, Regier D (2005). Patterns and quality of treatment for patients with schizophrenia in routine psychiatric practice. Psychiatric Services 56, 283-291.

World Health Organisation (1999). Schedules for Clinical Assessment in Neuropsychiatry (SCAN). WHO: Geneva. 